\title{
Characteristics distinguishing disseminated Mycobacterium tuberculosis (MTB) and non-tuberculous mycobacterial (NTM) infection in HIV patients
}

\author{
AC Bailey*1, A Samarawickrama ${ }^{1}$, F Ibrahim ${ }^{2}$, RD Barker ${ }^{1}$ and FA Post ${ }^{2}$
}

Address: ${ }^{1}$ King's College Hospital, London, UK and ${ }^{2}$ King's College London, London, UK

* Corresponding author

from Ninth International Congress on Drug Therapy in HIV Infection

Glasgow, UK. 9-13 November 2008

Published: 10 November 2008

Journal of the International AIDS Society 2008, I I (SuppI I):P262 doi:I0.II86/I758-2652-I I-SI-P262

This abstract is available from: http://www.jiasociety.org/content/I I/SI/P262

(C) 2008 Bailey et al; licensee BioMed Central Ltd.

\section{Purpose of the study}

The characteristics that distinguish disseminated MTB and NTM infection in patients with advanced HIV disease remain poorly studied. We aim to describe clinical, laboratory and radiological features of MTB and NTM and identify discriminatory findings.

\section{Methods}

We conducted a retrospective case note review of all patients with culture-proven disseminated mycobacterial disease at a UK centre from 2005-2007. Patients with infection in $\geq 2$ non-contiguous sites, or positive blood or bone marrow cultures, were included and stratified by causative pathogen. Categorical data were analysed by Fisher's exact test and non-categorical data by rank sum test.

\section{Summary of results}

Of the 64 patients with confirmed mycobacterial infection, 31 had disseminated disease (MTB:21, NTM:10 [nine due to $M$. avium Complex]). Of these, $81 \%$ were black African, 45\% male, and median age was 34 years. Patients with NTM had lower CD4 T-cell counts, more prior or concurrent AIDS-defining illnesses, and were more frequently taking HAART at the time of mycobacterial diagnosis. Six NTM infections and one MTB infection appeared to be unmasked by HAART. Clinical features at presentation were non-discriminatory. On imaging, patients with MTB more often had parenchymal lung disease, whilst thoracic and abdominal lymphadenopathy was common in both groups. None of the patients with NTM had AFB smear positive respiratory specimens. Whereas the yield of blood cultures was low in patients with MTB, bone marrow specimens were diagnostic in all patients. Mortality was $8 \%$ for MTB and 30\% for NTM cases. Immune reconstitution disease was observed in $52 \%$ of MTB and $30 \%$ of NTM patients. (Table 1.)

\section{Conclusion}

Clinical and laboratory characteristics of patients with MTB and NTM overlap. In patients with suspected disseminated mycobacterial infection, prior or concurrent AIDS defining illnesses and recent HAART initiation favour NTM, while $>100$ CD4 T-cells $/ \mathrm{mm}^{3}$ and parenchymal lung disease are suggestive of MTB. 
Table I:

\begin{tabular}{|c|c|c|c|}
\hline & MTB $(n=2 I)$ & NTM $(n=10)$ & p value \\
\hline Prior/concurrent AIDS-defining illness (\%) & $2(10)$ & $7(70)$ & 0.001 \\
\hline Median CD4 count at MTB/NTM diagnosis, cells/mm3 (IQR) & $5 I(13-142)$ & $20(5-33)$ & 0.049 \\
\hline On HAART at MTB/NTM diagnosis (\%) & $3(14)$ & $6(60)$ & 0.015 \\
\hline Parenchymal lung disease on CT scan* (\%) & $17(90)$ & $4(44)$ & 0.02 \\
\hline Thoracic/abdominal lymphadenopathy on CT or US scan* (\%) & 19(91) & $8(80)$ & 0.577 \\
\hline Positive AFB smear on sputum/BAL* (\%) & $7(44)$ & $0(0)$ & NA \\
\hline Positive sputum/BAL culture* (\%) & $12(86)$ & $6(86)$ & 1 \\
\hline Positive blood culture* (\%) & $\mathrm{I}(\mathrm{II})$ & $6(86)$ & 0.009 \\
\hline Positive bone marrow culture and/or histology* (\%) & $6(100)$ & $7(100)$ & NA \\
\hline
\end{tabular}

*In those who had investigation(s) performed.

Publish with Biomed Central and every scientist can read your work free of charge

"BioMed Central will be the most significant development for disseminating the results of biomedical research in our lifetime." Sir Paul Nurse, Cancer Research UK

Your research papers will be:

- available free of charge to the entire biomedical community

- peer reviewed and published immediately upon acceptance

- cited in PubMed and archived on PubMed Central

- yours - you keep the copyright 